\title{
VALIDATION OF MOVEMENT OVER A BELT CONVEYOR DRUM
}

\author{
Jiri Rozbroj', Jan Necas' ${ }^{1}$ Daniel Gelnar', Jakub Hlosta', Jiri Zegzulka' \\ 1 VSB-Technical University of Ostrava, ENET Centre, 17. listopadu 15/2172, 70833 Ostrava-Poruba, Czech \\ Republic, e-mail: univerzita@vsb.cz, jiri.rozbroj@vsb.cz
}

Received: 2017.04.15

Accepted: 2017.05.08

Published: 2017.06.01

\begin{abstract}
This paper presents the use of new modern methods for the research of movement of material on a belt conveyor. One of the innovative methods is Particle Image Velocimetry (PIV), which was used to scan and assess the two-dimensional vector field of speed of particles on the belt conveyor. Outputs from PIV were compared to simulations of the same transport process. These simulations were performed using the Discrete Element Method (DEM). Four transport speeds of material were assessed for a real and simulative belt conveyor model. Software tracking of particle movement was used to determine and compare the trajectories of paths of particles leaving the belt conveyor drum. Validation of the DEM simulation of material movement over a belt conveyor drum using PIV provided acceptable results in the area of particle speed fields. Comparison of the particle path trajectory corresponds to the preliminary hypothesis which leads to calibration of the DEM simulation. The results and assessment of this paper were created based on validation.
\end{abstract}

Keywords: Discrete Element Method, belt conveyor, Particle Image Velocimetry, trajectory of particles.

\section{INTRODUCTION}

The reliability and service life of belt conveyors is an increasingly important issue. The reason is the growing utilization of these conveyors in various industries. Dynamic stress leads to frequent damage of conveyor belts [1]. Various studies, simulations and tests of dynamic processes play an important role in this issue $[2,3,4,5$, $6,7]$. The aim is to increase their efficiency and reliability. The overflow of material over the end drum is a very frequently addressed issue. In this respect the transition point between two conveyor belts [8], setting of knock-down plates or prevention of abrasive degradation of material particles upon landing $[9,10]$ is addressed. The movement of material leaving the belt conveyor at its end and continuing by flight in the air along a flight curve is a frequently addressed issue in relation to other equipment or technologies [11]. The material movement trajectory is affected by numerous factors, such as, for example, belt conveyor speed and the properties of the transported material [12]. Due to these and other factors it is not easy to accurately determine the trajectory shape. This issue is resolved, for example, by Hastie [13].

The Discrete Element Method ("DEM") provides a new method of utilizing a simulation environment to design a transport process or equipment $[14,15]$. The opportunities of simulation modelling contribute to substantial time savings not only during the development of new equipment, but also during optimization of existing equipment $[16,17]$. The input parameters entered into the DEM are mechanical-physical parameters which describe the particular material. These properties include, for example, grain size and shape, material density, shear modulus and the Poisson constant. These parameters affect the weight of the grain, apparent density, apparent angle and other parameters. In most applications the friction coefficient is the domi- 

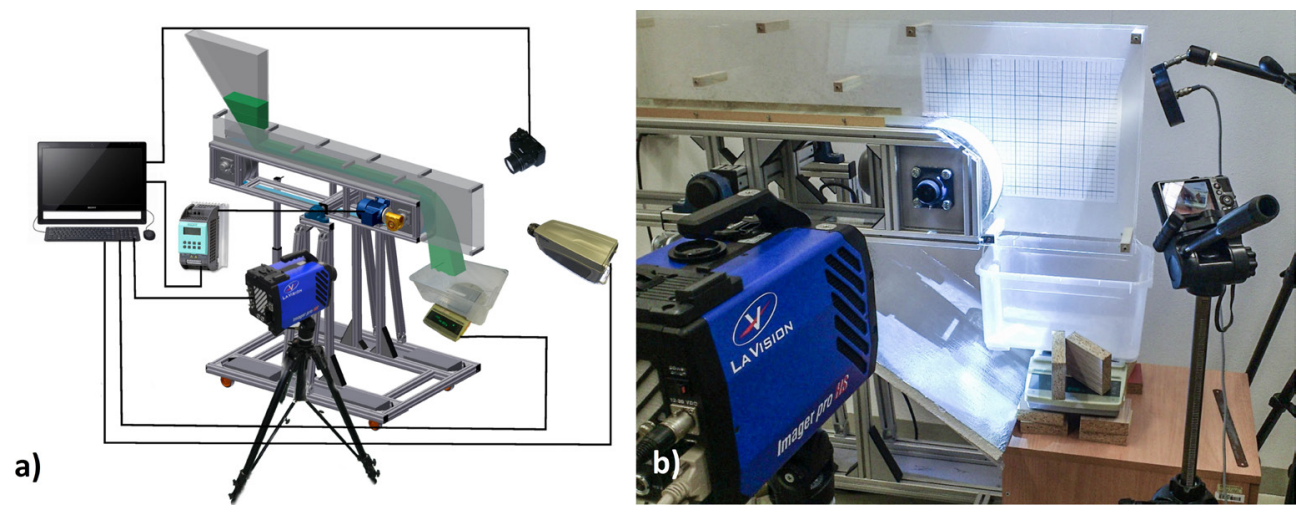

Fig. 1. Method of measurement on a realistic model: a) diagram, b) pre-measurement status

nant parameter for interaction between the materials used. The determination of these and other parameters contributes to simulation accuracy [18]. This also includes verification of input data correctness for the DEM and calibration of these models $[19,20]$.

Particle Image Velocimetry ("PIV") is often used for experimental measurement of the flow of particles and liquids. It is an optical method based on the visualization of the flow. It is used to measure the instantaneous speed of particles in various media such as water or air, but also in particulate materials. The monitored phenomenon is usually recorded by a high-speed CCD camera. Software calculation is used to assess the two-dimensional vector field of speed from the recording of particle movement [21].

This paper utilizes PIV to determine the flow speed of material leaving the model of the horizontal belt conveyor. The determined trajectories of the grains of transported material, recoded by the high-speed camera, were compared with the DEM simulations.

\section{METHODS AND EXPERIMENTS}

The experiments were conducted on a realistic horizontal belt conveyor model. The transport length of the equipment was $1 \mathrm{~m}$ and the belt width was $100 \mathrm{~mm}$. The conveyor belt was treated with an external protective PVC layer. Side guides made from plastic glass were installed along the entire transport length. At the entry point the conveyor was equipped with a hopper with a shutoff gate. After opening the shutoff gate it was possible to let the transported material into the equipment. At the end of the transport equipment material was collected into a box, which was weighed during measurement and recorded by a digital camera. The process of emptying the equipment at the point of the drive drum was recorded by two high-speed CCD cameras. The main camera (LaVision Imager Pro HS) monitored the process in the axial direction of the drive drum and the auxiliary camera (Olympus I-Speed 2) monitored the radial direction. The measurement setup is illustrated in Figure 1.

The data from the main camera was used to determine the shape of the curve of the transported material and speed field. The auxiliary camera was used as an additional device and its data was not the subject of this paper. The scanning frequency of the camera was always set to 400 frames per second. At a maximum definition of 2016 x 2016 pixels and frequency of $400 \mathrm{fps}$ the main camera was able to save 3600 images per single recording sequence. The duration of the recording of up to $9 \mathrm{~s}$ corresponded to these parameters. This time period of one recording sequence was sufficient for all experiments with the conveyor emptying processes. The assessment of the recorded material speed field was performed using PIV software DaVis 8.0.8 from LaVision. The trajectory was assessed by tracing particle movement using I-Speed PC software. Individual tracings were performed by always selecting one particle from the middle layer of the material on the conveyor. Movement was monitored in a plane perpendicular to the axis of rotation of the conveyor drive drum. By drafting the obtained coordinates for two-dimensional space the curves of possible mean particle flight paths were determined.

The speed of the conveyor belt for the experiments was set by the speed of the drive drum using a frequency converter and laser revolution sensor. The belt speeds $\mathrm{v}_{\mathrm{b}}$ were set to $0.5,0.8$, 
Table 1. Material properties

\begin{tabular}{|c|c|c|c|c|}
\hline Input parameter & Belt & Plastic & Metallic & Glass \\
\hline Poisson's Ratio $(-)$ & 0.38 & 0.39 & 0.31 & 0.23 \\
\hline Shear Modulus $(\mathrm{Pa})$ & $1 \mathrm{e}+07$ & $9 \mathrm{e}+08$ & $7.4 \mathrm{e}+10$ & $3 \mathrm{e}+08$ \\
\hline Density $\left(\mathrm{kg} \cdot \mathrm{m}^{-3}\right)$ & 1300 & 1780 & 7800 & 2036 \\
\hline
\end{tabular}

Table 2. Contacts parameters

\begin{tabular}{|c|c|c|c|c|}
\hline $\begin{array}{c}\text { Input } \\
\text { parameter }\end{array}$ & $\begin{array}{c}\text { Glass- } \\
\text { Glass }\end{array}$ & $\begin{array}{c}\text { Glass- } \\
\text { Belt }\end{array}$ & $\begin{array}{c}\text { Glass- } \\
\text { Plastic }\end{array}$ & $\begin{array}{c}\text { Glass- } \\
\text { Metallic }\end{array}$ \\
\hline $\begin{array}{c}\text { Coefficient of } \\
\text { Restitution (-) }\end{array}$ & 0.9 & 0.5 & 0.8 & 0.8 \\
\hline $\begin{array}{c}\text { Coefficient of } \\
\text { Static Friction (-) }\end{array}$ & 0.3 & 0.7 & 0.32 & 0.2 \\
\hline $\begin{array}{c}\text { Coefficient of } \\
\text { Rolling Friction (-) }\end{array}$ & 0.01 & 0.01 & 0.01 & 0.01 \\
\hline
\end{tabular}

1 and $1.25 \mathrm{~m} \cdot \mathrm{s}^{-1}$. The material transported was spherical glass particles with a diameter of $4 \mathrm{~mm}$.

The simulation model of the belt conveyor, whose dimensions were based on a realistic model, was created in a CAD program. It was then imported into the EDEM Academic application in STEP format. The input material parameters for the DEM simulation are shown in Table 1. Materials called Belt, Plastic and Metallic were used for the geometry of the belt conveyor model. The Glass material was used as the transported material. The interactions between the respective materials are shown in Table 2 . These values were determined experimentally.

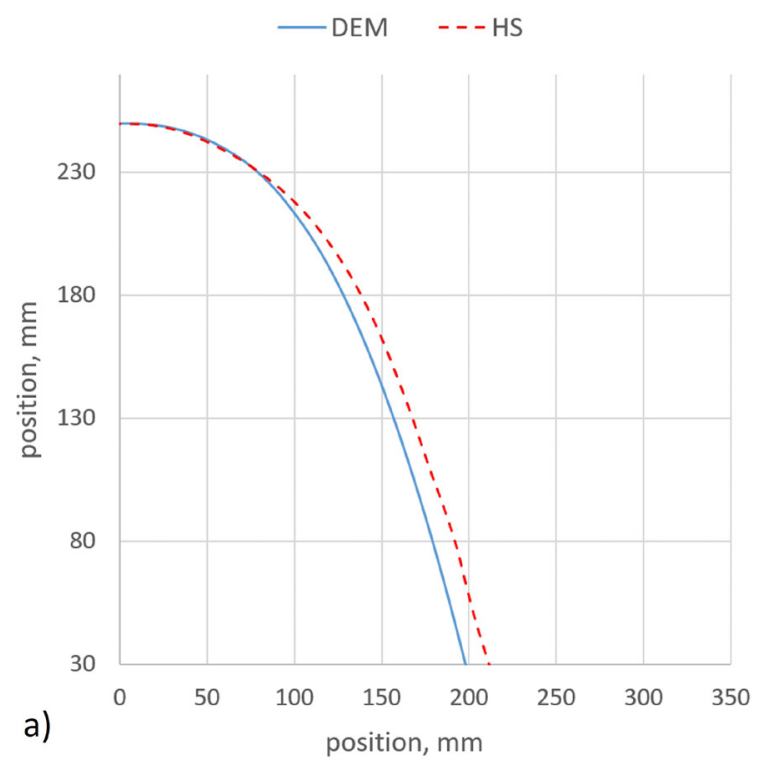

The determination of curves of mean particle flight paths from simulations was performed in the EDEM Academic application. The method and principle was very similar to tracing performed using I-Speed PC software. A particle in the middle layer was monitored exactly as in the realistic experiment.

\section{RESULTS AND DISCUSSION}

The resultant curves for possible mean particle flight paths from the realistic (HS) and simulation (DEM) experiment were compared in Figure 2 and Figure 3. A unified coordinate system was used. The differences in curve overlay can be best assessed from the maximum achieved distance of particles in the horizontal direction. The smallest differences in curve shape in this respect were achieved for a belt speed $\mathrm{v}_{\mathrm{b}}=0.5 \mathrm{~m} \cdot \mathrm{s}^{-1}$. The value of the maximum length coordinate in a horizontal direction from DEM was $6.6 \%$ less than the value from the high-speed camera. The achieved distances of particles in the horizontal direction changed with the increasing belt speed. However, the biggest difference in curve shape was not determined for the highest used belt speed $\mathrm{v}_{\mathrm{b}}=1.25 \mathrm{~m} \cdot \mathrm{s}^{-1}$, but for $\mathrm{v}_{\mathrm{b}}=1 \mathrm{~m} \cdot \mathrm{s}^{-1}$. The value from DEM was $16.2 \%$ lower than the value from the high-speed camera. For belt speed $\mathrm{v}_{\mathrm{b}}=$ $0.8 \mathrm{~m} \cdot \mathrm{s}^{-1}$ the value from DEM was $13.4 \%$ lower than from the high-speed camera and for belt speed $\mathrm{v}_{\mathrm{b}}=1.25 \mathrm{~m} \cdot \mathrm{s}^{-1}$ it was $13.2 \%$ lower.

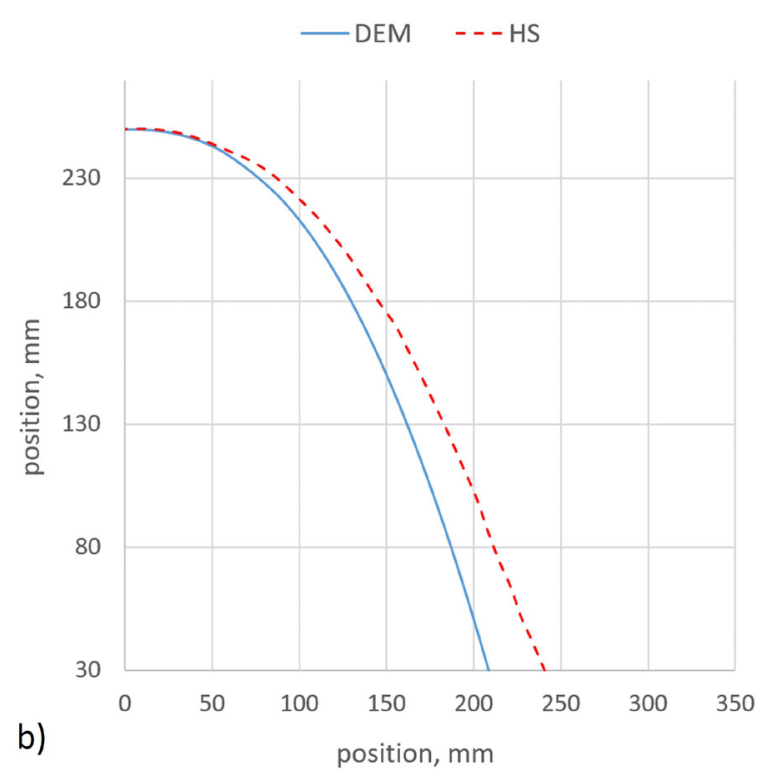

Fig. 2. Comparison of flight curve shape: a) $\mathrm{v}_{\mathrm{b}}=0.5 \mathrm{~m} \cdot \mathrm{s}^{-1}$, b) $\mathrm{v}_{\mathrm{b}}=0.8 \mathrm{~m} \cdot \mathrm{s}^{-1}$ 

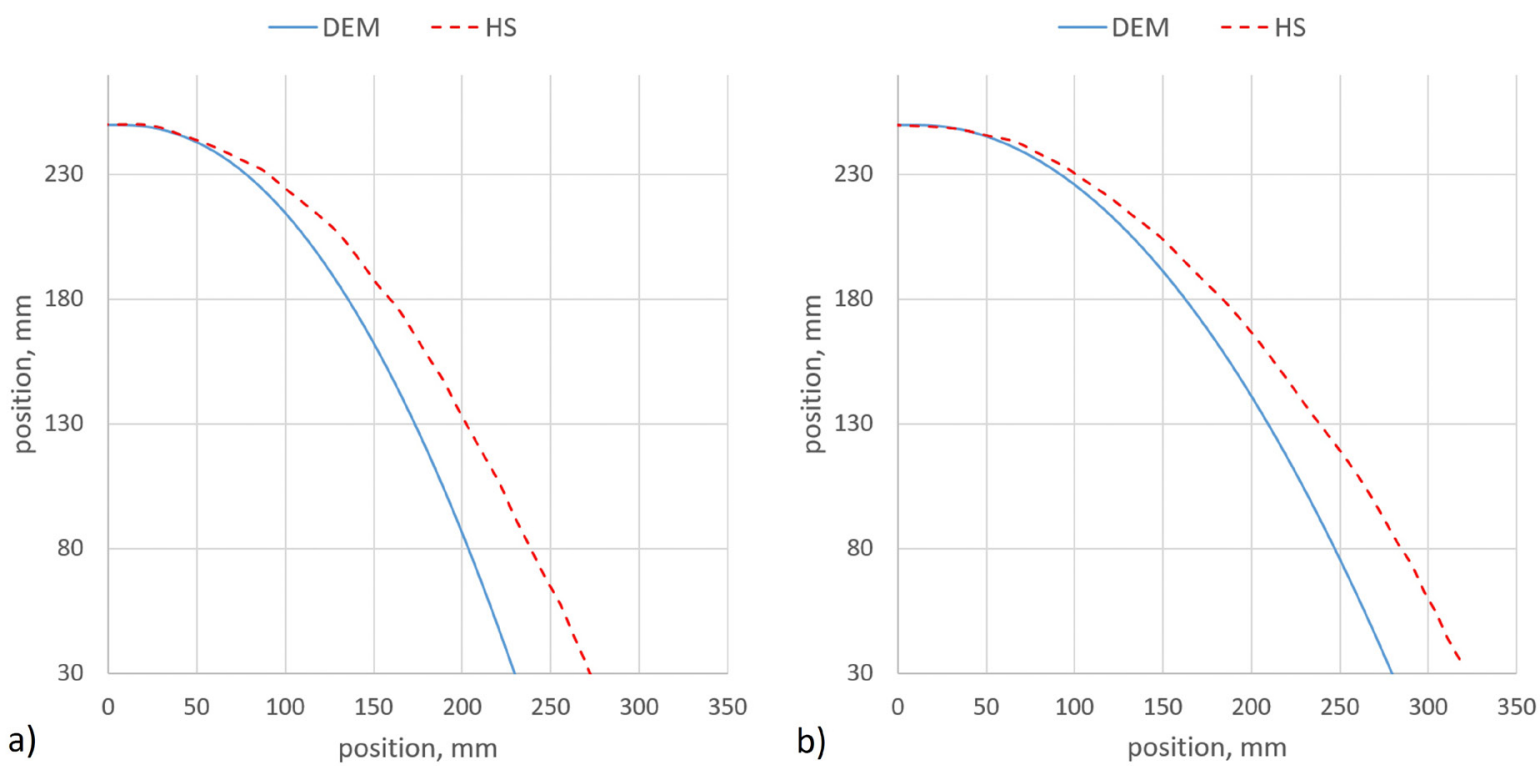

Fig. 3. Comparison of flight curve shape: a) $\mathrm{v}_{\mathrm{b}}=1 \mathrm{~m} \cdot \mathrm{s}^{-1}$, b) $\mathrm{v}_{\mathrm{b}}=1.25 \mathrm{~m} \cdot \mathrm{s}^{-1}$

Figures 4 to 7 show speed comparison of transported material between DEM and PIV. During visual observation the difference in transported material speed between DEM and PIV was negligible. For $\mathrm{v}_{\mathrm{b}}=0.5 \mathrm{~m} \cdot \mathrm{s}^{-1}$ (Fig. 4) and $0.8 \mathrm{~m} \cdot \mathrm{s}^{-1}$ (Fig. 5) there was an evident difference in the dispersion of particles between PIV and DEM. DEM demonstrated a higher dispersion of particles at the conveyor exit. For $\mathrm{v}_{\mathrm{b}}=1$ and $1.25 \mathrm{~m} \cdot \mathrm{s}^{-1} \mathrm{a}$ smaller dispersion of particles was seen in DEM compared to outputs from PIV. Further, there was an evident difference in graphic output between PIV and DEM in the green bordered area of material flow. This area is displayed only for outputs from PIV. This is a transition area between the current material speed and zero ambient speed. This transition area was computationally averaged by the DaVis software.

From the comparison of PIV and DEM outputs it was concluded that although the resultant speed range between DEM and PIV concurred, the flow profile of the transported material was not identical. One of the possible causes of this non-conformity, which was determined by the method of particle tracing, could even be the optical distortion of the image. This deformation was caused by a combination of the small distance of the main camera from the recorded object and the
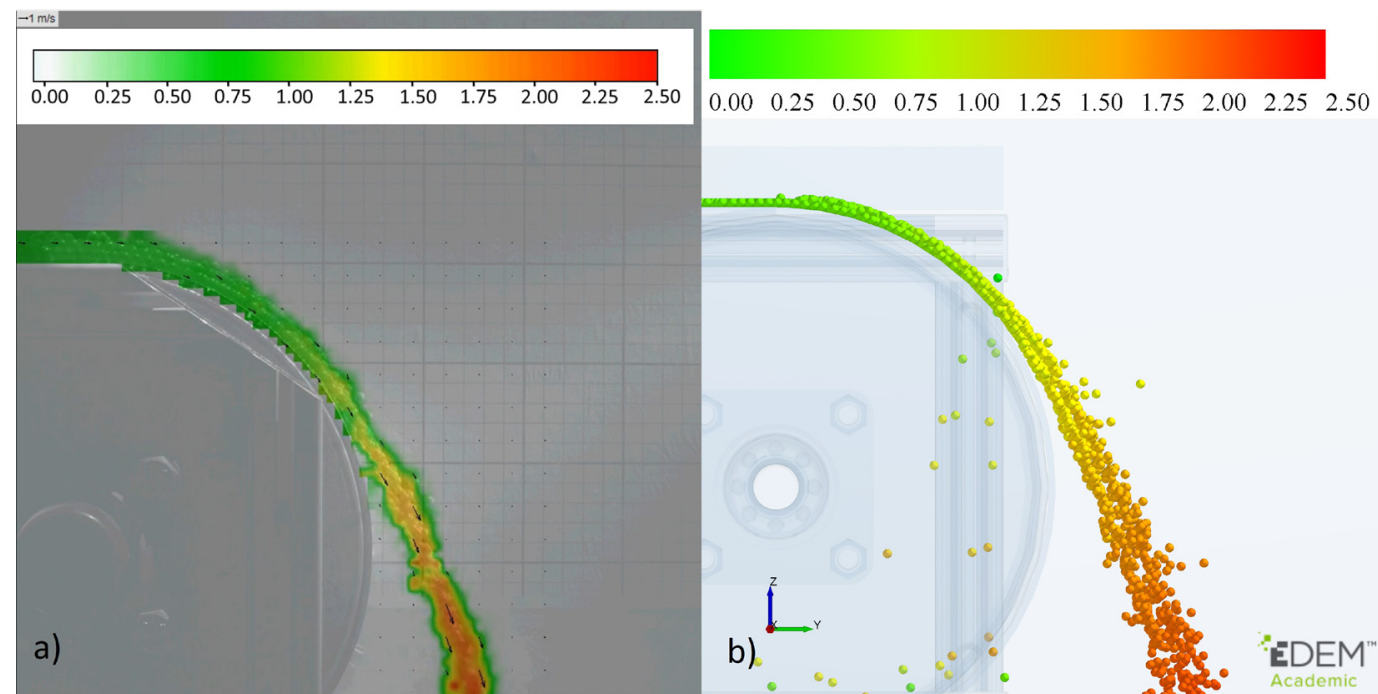

Fig. 4. Material speed for $\mathrm{v}_{\mathrm{b}}=0.5 \mathrm{~m} \cdot \mathrm{s}^{-1}$ : a) PIV output, b) DEM output 

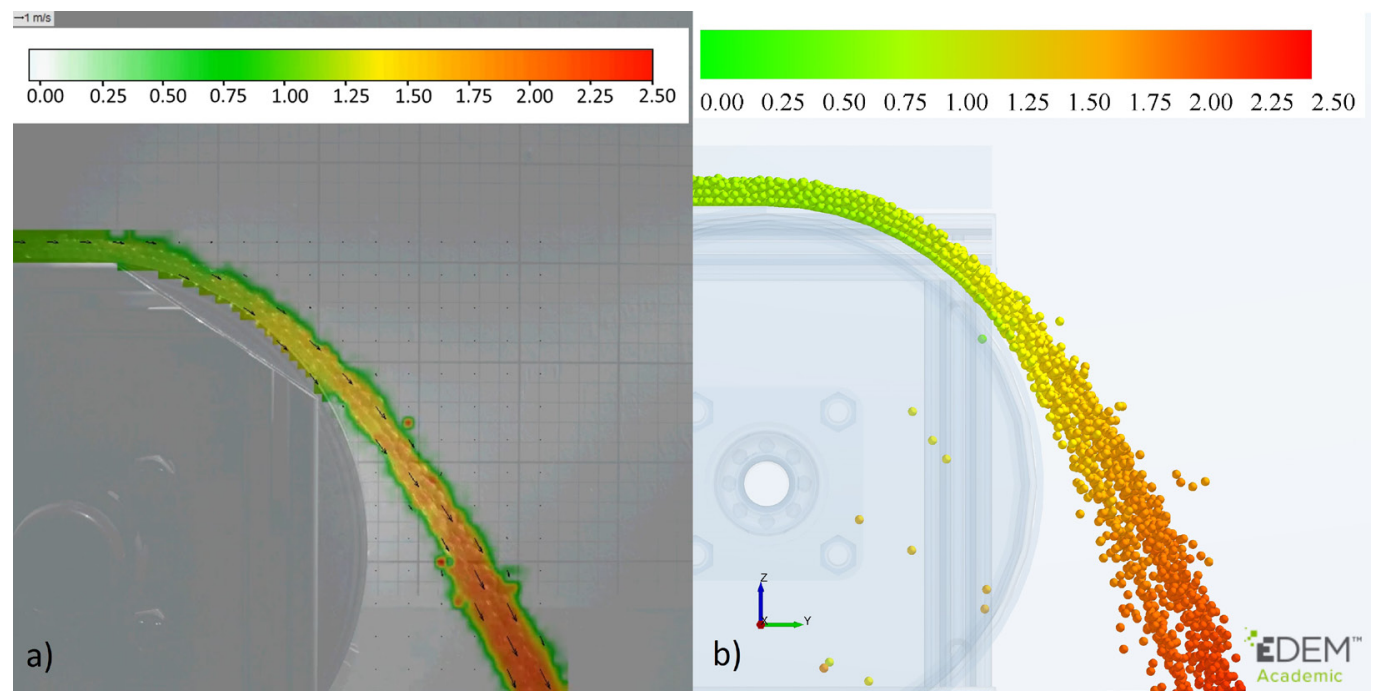

Fig. 5. Material speed for $\mathrm{v}_{\mathrm{b}}=0.8 \mathrm{~m} \cdot \mathrm{s}^{-1}$ : a) PIV output, b) DEM output
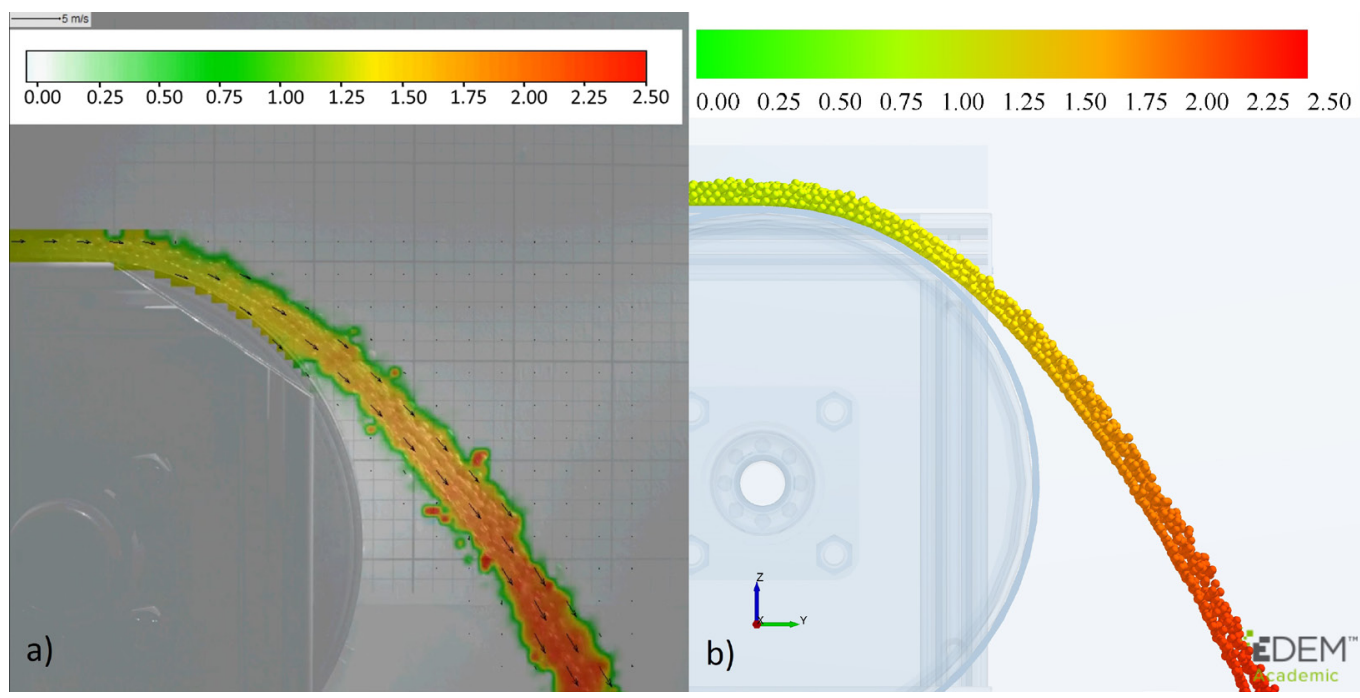

Fig. 6. Material speed for $\mathrm{v}_{\mathrm{b}}=1 \mathrm{~m} \cdot \mathrm{s}^{-1}$ : a) PIV output, b) DEM output
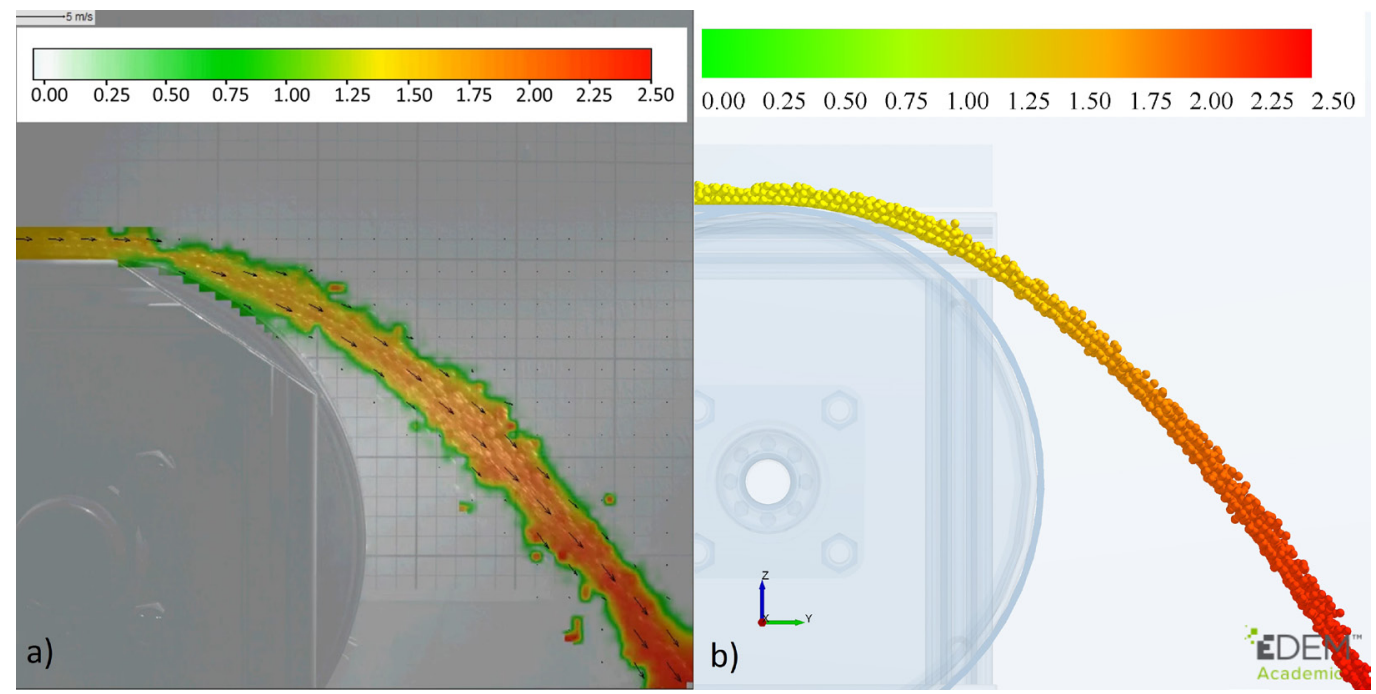

Fig. 7. Material speed for $\mathrm{v}_{\mathrm{b}}=1.25 \mathrm{~m} \cdot \mathrm{s}^{-1}$ : a) PIV output, b) DEM output 
lens with a lower focal length value. The use of a greater distance of the camera from the recorded object, together with a higher focal length value of the lens, could partly eliminate these impacts.

\section{CONCLUSIONS}

This paper focused purely on the validation of movement of material over a belt conveyor drum. For further broader use and increase in accuracy of outputs it would be necessary to calibrate DEM simulations. From this paper it is clear that validation is an important process and finding in which direction the experiments will develop further. Use of the PIV method is very desirable for the issue in question and offers a new approach to analysis of movement of material on a conveyor. This method can be used to determine and research substantial regularities, differences and effects impacting differently on realistic and simulated experiments. Parameters affecting simulation calibration and optimization can be verified only based on outputs from validation. Based on the results obtained in this paper it is possible to obtain a picture about the possible accuracy of the DEM and the advantage of using PIV for the validation of overflow of transported material on a belt conveyor. Further, based on the validation of DEM simulations with the help of PIV, it is possible to optimize the experimental process in order to achieve better results. These, and other researched aspects, are the subject of further work on this topic.

\section{Acknowledgements}

This paper was conducted within the framework of the project LO1404: Sustainable development of ENET Centre.

\section{REFERENCES}

1. Fedorko G., Molnar V., Grincova A., Dovica M., Toth T., Husakova N., Taraba V. and Kelemen M. Failure analysis of irreversible changes in the construction of rubber-textile conveyor belt damaged by sharp-edge material impact. Engineering Failure Analysis, 39, 2014, 135-148.

2. Molnar V., Fedorko G., Stehlikova B., Michalik P. and Weiszer M. A regression model for prediction of pipe conveyor belt contact forces on idler rolls. Measurement, 46(10), 2013, 3910-3917.
3. Molnar V., Fedorko G., Stehlikova B., Michalik P. and Kopas M. Mathematical models for indirect measurement of contact forces in hexagonal idler housing of pipe conveyor. Measurement, 47, 2014, 794-803.

4. Michalik P. and Zajac J. Using of computer integrated system for static tests of pipe conveyer belts. Proc. of 13th International Carpathian Control Conference (ICCC), High Tatras, Slovakia 2012, 480-485.

5. Bigos P., Kulka J., Kubin K. and Mantic M. Professional verification of crane track beams in heavy metallurgical operation by means of tensometry, Reliability and Risk Analysis, 2009, 30-37.

6. Gajdos I., Slota J., Spisak E., Jachowicz T. and TorSwiatek A. Structure and tensile properties evaluation of samples produced by Fused Deposition Modeling, Open Engineering, 6, 2016, 86-89.

7. Debski H., Koszalka G. and Ferdynus M. Application of FEM in the analysis of the structure of a trailer supporting frame with variable operation parameters, Eksploatacja I Niezawodnosc - Maintenance and Reliability, 14, 2012, 107-113.

8. Wensrich Ch.M. Evolutionary optimisation in chute design. Powder technology, 138(2), 2003, 118-123.

9. Grima A.P. and Wypych P.W. Investigation into calibration of discrete element model parameters for scale-up and validation of particle-structure interactions under impact conditions. Powder Technology, 212(1), 2011, 198-209.

10. Molnar V., Fedorko G., Husakova N., Král' J.J. and Ferdynus M. Energy calculation model of an outgoing conveyor with application of a transfer chute with the damping plate. Mechanical Sciences, 7(2), 2016, 167.

11. Hastie D.B. and Wypych P.W. Experimental validation of particle flow through conveyor transfer hoods via continuum and discrete element methods. Mechanics of Materials, 42(4), 2010, 383-394.

12. Xie L., Zhong W., Zhang H., Yu A., Qian Y. and Situ Y. Wear process during granular flow transportation in conveyor transfer. Powder Technology, 288, 2016, 65-75.

13. Hastie D.B. and Wypych P.W. Evaluation of belt conveyor trajectories. In: 6th International Conference for Conveying and Handling of Particulate Solids: 3-7 August 2009, Brisbane Convention \& Exhibition Centre, Queensland, Australia. Engineers Australia, 2009, 299-305.

14. Gröger T. and Katterfeld A. Application of the Discrete Element Method in Materials Handling-Part 3: Transfer Stations. Bulk Solids Handling, 27(3), 2007, 158-166.

15. Cleary P.W. Large scale industrial DEM modelling. Engineering Computations, 21(2/3/4), 2004, 169-204.

16. Guo Y.C., Wang S., Hu K. and Li D. Optimization 
and experimental study of transport section lateral pressure of pipe belt conveyor. Advanced Powder Technology, 27(4), 2016, 1318-1324.

17. Grima A.P., Fraser T, Hastie D.B and Wypych P.W. Discrete element modelling: trouble-shooting and optimisation tool for chute design, 2011, 1-26.

18. Coetzee C. J. and Els D. N. J. Calibration of discrete element parameters and the modelling of silo discharge and bucket filling. Computers and Electronics in Agriculture, 65(2), 2009, 198-212.
19. Coetzee C. J. Review: Calibration of the Discrete Element Method. Powder Technology, 310, 2017, 104-142.

20. Grima A. and Wypych P. Discrete element simulation of a conveyor impact-plate transfer: calibration, validation and scale-up. Australian Bulk Handling Review, 3, 2010, 64-72.

21. Ziegenhein T. and Lucas D. On sampling bias in multiphase flows: Particle image velocimetry in bubbly flows. Flow Measurement and Instrumentation, 48, 2016, 36-41. 